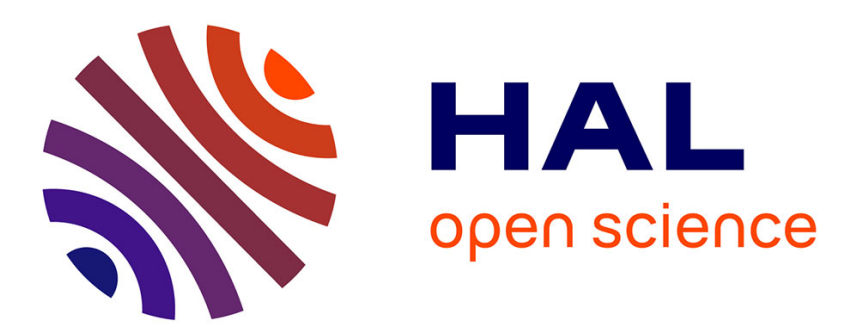

\title{
A two-layer depth-averaged model for both the dilute and the concentrated parts of pyroclastic currents \\ Karim Kelfoun
}

\section{To cite this version:}

Karim Kelfoun. A two-layer depth-averaged model for both the dilute and the concentrated parts of pyroclastic currents. Journal of Geophysical Research: Solid Earth, 2017, 122 (6), pp.4293 - 4311. 10.1002/2017JB014013 . hal-01684793

\section{HAL Id: hal-01684793 \\ https://hal.uca.fr/hal-01684793}

Submitted on 15 Jan 2018

HAL is a multi-disciplinary open access archive for the deposit and dissemination of scientific research documents, whether they are published or not. The documents may come from teaching and research institutions in France or abroad, or from public or private research centers.
L'archive ouverte pluridisciplinaire HAL, est destinée au dépôt et à la diffusion de documents scientifiques de niveau recherche, publiés ou non, émanant des établissements d'enseignement et de recherche français ou étrangers, des laboratoires publics ou privés. 


\title{
A two-layer depth-averaged model for both the dilute and the concentrated parts of pyroclastic currents.
}

\author{
Karim Kelfoun \\ Université Clermont Auvergne, CNRS, IRD, OPGC, Laboratoire Magmas et \\ Volcans, F-63000 Clermont-Ferrand, France.
}

\begin{abstract}
Pyroclastic currents are very destructive and their complex behavior makes the related hazards difficult to predict. A new numerical model has been developed to simulate the emplacement of both the concentrated and the dilute parts of pyroclastic currents using two coupled depthaveraged approaches. Interaction laws allow the concentrated current (pyroclastic flow) to generate a dilute current (pyroclastic surge) and, inversely, the dilute current to form a concentrated current or a deposit. The density of the concentrated current is assumed to be constant during emplacement, whereas the density of the dilute current changes depending on the particle supply from the concentrated current and the mass lost through sedimentation. The model is explored theoretically using simplified geometries as a proxies for natural source conditions and topographies. It reproduces the relationships observed in the field between the surge genesis and the topography: the increase in surge production in constricted valleys, the decoupling between the concentrated and the dilute currents and the formation of surge-derived concentrated flows. The strong non linear link between the surge genesis and the velocity of the concentrated flow beneath it could explain the sudden occurrence of powerful and destructive surges and the difficulty of predicting this occurrence. A companion paper compares the results of the model with the field data for the eruption of Merapi in 2010 [Kelfoun et al.,
\end{abstract}


submitted] and demonstrates that the approach is able to reproduce the natural emplacement of the concentrated and the dilute pyroclastic currents studied with good accuracy.

\section{Introduction}

Pyroclastic currents are fast-moving density currents composed of hot gas and rock fragments. For small to medium-scale eruptions, generated by column collapse or dome collapse, pyroclastic density currents (PDC) are generally formed of two distinct parts: a concentrated and a dilute part [Lacroix, 1904; Sparks et al., 1973, Walker and Wilson, 1983; Valentine and Fisher, 1986]. The concentrated part, termed block-and-ash flow, scoria flow or pumice flow depending on its composition, or more generally called pyroclastic flow [Branney and Kokelaar, 2002], follows existing valleys and is sensitive to meter-scale variations in the topography. Following the nomenclature used in the volcanological community, the term 'flow' will be used here for the concentrated part of PDCs only [Branney and Kokelaar, 2002]. Particle concentration in the flow is close to particle concentration at rest, which means that particle interactions probably play a major role in its dynamics. The dilute part of the current is called dilute current, pyroclastic surge or ash-cloud surge. It is formed of fine particles held in suspension by turbulent gas [e.g. Branney and Kokelaar, 2002; Valentine, 1987]. Ash-cloud surges are generally several tens of meters in thickness but they often leave deposits of only a few centimetres-decimetres due to their low particle concentrations (about 1\% in volume [Druitt, 1998]). Note that this concentration is higher than the maximal concentration of $0.1 \%$ that defines dilute mixtures in the multiphase flow literature, i.e. below which collisions can be neglected [e.g. Elgobashi, 1994]. Pyroclastic surges are less confined by the topography, escape easily from the valleys and are very dangerous for the inhabitants. They are believed to be stratified, their density increasing downward [Valentine, 1987]. 
The two types of currents interact during their emplacement and can exchange particles and gas. The particles, falling down to the ground through sedimentation of the dilute current, either form a deposit, increase the volume of the concentrated flow or create a surge-derived pyroclastic flow [Druitt and Sparks, 1982; Calder et al., 1999; Druitt et al., 2002]. Inversely, a dilute current can be generated by the concentrated flow and then can acquire its own dynamics [Fisher, 1979; Nakada and Fujii, 1993; Yamamoto et al. 1993; Fisher, 1995; Kelfoun et al., 2000; Bourdier and Abdurachman, 2001; Breard et al., 2016].

Several approaches have been used to simulate PDCs on digital elevation models (DEMs). For example, the kinematic approach only simulate flow trajectories, considering the flow as a punctual mass [Sheridan and Malin, 1983, Beget and Limke, 1988; McEwen and Malin, 1989; Rossano et al., 2004 and Saucedo et al., 2005]. In the multiphase approach, all the phases (different classes of particles, gases of various compositions) are taken into account and interact together in 3D [e.g. Valentine and Wohletz, 1989; Valentine et al., 1992; Neri and Macedonio, 1996; Neri et al., 2003; Dartevelle et al., 2004; Esposti Ongaro et al., 2008; Esposti Ongaro et al., 2012]. In the depth-averaged method, all the physical properties and the equations are integrated perpendicular to the ground (or sometimes vertically). Compared to the $3 \mathrm{D}$ solving of the multiphase approach, this integration allows to speed up the calculation time and to take into account small details of the topography (models can reproduce the natural runout of geophysical flows on high resolution accurate topographies $(<5 \mathrm{~m})$ in a few tens of minutes). However, a limit of the approach is its accuracy on complex topographies with high curvatures. For a better understanding of the limits and new developments of the depth-averaged approach on complex topographies, the reader can refer to Hutter et al. (2005), Luca et al. (2009), CastroOrgaz et al. (2015), Luca et al. (2016). The integration of the depth-averaged approach also implies that the flow is wider than it is thick and that vertical acceleration is negligible. The depth-averaged method is often used to simulate granular flows in the laboratory [Savage and 
Hutter, 1989; Pouliquen and Forterre, 2002; Gray et al., 2003] and geophysical flows like mud flows, pyroclastic flows, landslides, debris avalanches and snow avalanches [e.g. Itoh et al., 2000; Heinrich et al., 2001; Turnbull and Bartelt, 2003; Pitman et al., 2003; Kelfoun and Druitt, 2005; Sheridan et al., 2005; Patra et al., 2005; Lucas and Mangeney, 2007; Kelfoun et al., 2009]. The depth-averaged method has also been developed to take into account 2 phases, solid and water, for the simulation of debris flows [e.g. Iverson and Denlinger, 2001; Córdoba et al., 2015], and to simulate granular flows fluidized by gases [Gueugneau et al., 2017].

The integration and resolution of the depth-averaged methods is mainly done for currents whose density is constant in time and space, and it has been shown that it can reproduce accurately the velocity, deposit thickness and extension of concentrated pyroclastic flows [Kelfoun et al., 2009]. Theoretically, the depth-averaged approach is less adapted for dilute currents because of their vertical variations in density. However, the displacement of a density current is due to a pressure gradient parallel to the ground and the pressure is more influenced by the total mass above a given point than by its vertical variations. Based on this reasoning, Doyle et al. [2008] have explored the formation of concentrated flow from a dilute current using a depth-averaged model. Their approach is clearly simplified compared to the multiphase approach but the limited number of variables of the model allows the influence of each one on the global results to be studied.

The aim of the present work is to present a new depth-averaged model that simulates both the concentrated and the dilute part of pyroclastic currents and their interactions. The dilute current can form a concentrated flow, as in Doyle et al. [2008]. The innovation in our model is that, inversely, the concentrated flow is able to form a dilute current, as often occurs during dome collapses. The model also runs on a pseudo 3D surface (Digital Elevation Model of volcanic topography) and the concentrated part uses a rheology estimated from field observations, which 
allows the dilute current to form either a deposit or a surge-derived pyroclastic flow depending on the thickness deposited.

\section{The two-layer model}

The objective of this work is to develop the simplest model for concentrated and dilute currents that reproduces the first-order features of the natural phenomena. The simulation of the concentrated flow must approximate the velocity of the real flow, the covered area (extent, runout) and the deposit thickness. The model must also address the way the surge is generated by the concentrated flow (Fig. 1), as well as reproducing the velocity, the thickness of the surge and the area it covers. Finally, the surge should lose mass to form a deposit or a surge-derived pyroclastic flow compatible with natural observations. Other phenomena such as the effects of break in slope, the influence of river width changes and the decoupling between the concentrated and the dilute currents [e.g. Ogburn et al., 2014] must also be tested to assess the quality of the model.

\subsection{Dynamics of the concentrated flow}

The dynamics of the concentrated flow is calculated by solving depth-averaged equations of mass (1) and momentum balance, along $x$ in (2) and $y$ in (3), taking into account the mass of the particles exchanged with the dilute current.

$$
\begin{aligned}
& \frac{\partial h_{\mathrm{d}}}{\partial t}+\frac{\partial}{\partial x}\left(h_{\mathrm{d}} u_{x}\right)+\frac{\partial}{\partial y}\left(h_{\mathrm{d}} u_{y}\right)=\frac{\phi_{\mathrm{s}}-\phi_{\mathrm{m}}}{\rho_{\mathrm{d}}} \\
& \frac{\partial}{\partial t}\left(h_{\mathrm{d}} u_{x}\right)+\frac{\partial}{\partial x}\left(h_{\mathrm{d}} u_{x}^{2}\right)+\frac{\partial}{\partial y}\left(h_{\mathrm{d}} u_{x} u_{y}\right) \\
& =g h_{\mathrm{d}} \sin \alpha_{x}-\frac{1}{2} \frac{\partial}{\partial x}\left(g h_{\mathrm{d}}^{2} \cos \alpha_{x}\right)+\frac{T_{x}}{\rho_{d}}+\frac{\phi_{\mathrm{s}}}{\rho_{\mathrm{d}}} v_{x}-\frac{\phi_{m}}{\rho_{\mathrm{d}}} u_{x}
\end{aligned}
$$




$$
\begin{aligned}
& \frac{\partial}{\partial t}\left(h_{\mathrm{d}} u_{y}\right)+\frac{\partial}{\partial x}\left(h_{\mathrm{d}} u_{x} u_{y}\right)+\frac{\partial}{\partial y}\left(h_{\mathrm{d}} u_{y}^{2}\right) \\
& =g h_{\mathrm{d}} \sin \alpha_{y}-\frac{1}{2} \frac{\partial}{\partial y}\left(g h_{\mathrm{d}}^{2} \cos \alpha_{y}\right)+\frac{T_{y}}{\rho_{d}}+\frac{\phi_{\mathrm{s}}}{\rho_{\mathrm{d}}} v_{y}-\frac{\phi_{m}}{\rho_{\mathrm{d}}} u_{y}
\end{aligned}
$$

where $h_{\mathrm{d}}$ is the thickness of the concentrated flow, $\mathbf{u}=\left(u_{x}, u_{y}\right)$ its velocity, $\alpha_{x}$ and $\alpha_{y}$ the slope of the topography in the $x$ and $y$ directions, $t$ the time and $\mathbf{v}=\left(v_{x}, v_{y}\right)$ the velocity of the surge (Fig. 1). The concentrated flow is considered to be of constant density, $\rho_{\mathrm{d}}$, in time and space allowing the mass balance to be simplified by a thickness balance in (1).

The variables $\phi_{\mathrm{m}}$ and $\phi_{\mathrm{s}}$ are the mass fluxes per square meter of the mixture of gas and particles that move from the concentrated to the dilute current (see section 2.3), and of particles that leave the dilute current through sedimentation (see section 2.4), respectively (Fig. 1). The terms at the right-hand side of equations $1-3$, which contain $\phi_{\mathrm{m}}$ and $\phi_{\mathrm{s}}$, govern the mass and momentum exchanges between the concentrated and the dilute currents.

The flow is slowed down by the resisting stress exerted by the ground, $\mathbf{T}=\left(T_{x}, T_{y}\right)$, which depends on the rheology of the flow. The rheology of pyroclastic flows is very complex and still not clearly understood. Kelfoun et al. [2009] and Kelfoun [2011] have shown that a plastic rheology forms flows and deposits whose characteristics are close to the natural phenomena in terms of extension, thickness, thickness variation, and velocity, although the reason why this is so is not fully understood [Kelfoun, 2011]. Kelfoun et al. [2009] also noted that a velocitydependent term could be added to the plastic rheology to better reproduce the natural emplacement of the Tungurahua pyroclastic flows, formed by the destabilisation of pyroclasts accumulated by fountaining. However, for such eruptions with a relatively small mass flux feeding the flow, the influence of this term on the dynamics was too small to be clearly identified from field observations. Charbonnier and Gertisser [2012] and Charbonnier et al. [2013] have reproduced the emplacement of the concentrated pyroclastic flows of the Merapi 
volcano for the 2006 and 2010 eruptions. They have confirmed that a plastic rheology captures the flow emplacement better than a Coulomb rheology and they have shown that, for the high mass flux related to a dome collapse, the additional term related to the square of the flow velocity must be used to reproduce the natural velocity of the flow. The retarding stress $\mathbf{T}$ they have used is expressed by:

$$
\mathbf{T}=-T_{0} \times \frac{\mathbf{u}}{\|\mathbf{u}\|}-a_{1} \rho_{d}\|\mathbf{u}\| \mathbf{u}
$$

and its components in $x$ and $y$ are $T_{x}=-T_{0} \frac{u_{x}}{\|\mathbf{u}\|}-a_{1} \rho_{d}\|\mathbf{u}\| u_{x}$ and $T_{y}=-T_{0} \frac{u_{y}}{\|\mathbf{u}\|}-a_{1} \rho_{d}\|\mathbf{u}\| u_{y}$.

The best value estimated by Charbonnier and Gertisser [2012] and Charbonnier et al. [2013] for the two Merapi eruptions is $a_{1}=0.01$. The velocity related term, $a_{1}$, influences the flow essentially during the initial phase, when both the mass flux and the flow velocity are high. It might correspond to an additional absorption of energy related to collisions and rock break-up during the lava dome destruction. Neither the temperature and its variations nor the erosion and the incorporation of substratum material in the flow [Bernard et al., 2014] are included in the present model. Aggradation is also not included in the simulation of the concentrated part, and the flow stops en masse according to the balance between driving stresses, retarding stresses and inertia.

\subsection{Dynamics of the dilute current}

In the same way as for the concentrated flow, the dilute current (i.e. pyroclastic surge) is simulated by equations of mass and momentum balance. However, a fourth equation must be added to the system because the density varies in time and space. The surge is considered to be incompressible and isothermal following Doyle et al. [2008; 2010]. The turbulent mixing is 
assumed to be sufficiently intense to maintain a uniform particle concentration perpendicular to the ground. The system describing the surge dynamics is then:

$$
\begin{aligned}
& \frac{\partial h_{\mathrm{s}}}{\partial t}+\frac{\partial}{\partial x}\left(h_{\mathrm{s}} v_{x}\right)+\frac{\partial}{\partial y}\left(h_{\mathrm{s}} v_{y}\right)=\frac{\phi_{\mathrm{m}}}{\rho_{\mathrm{m}}} \\
& \frac{\partial \rho_{\mathrm{s}} h_{\mathrm{s}}}{\partial t}+\frac{\partial}{\partial x}\left(\rho_{\mathrm{s}} h_{\mathrm{s}} v_{x}\right)+\frac{\partial}{\partial y}\left(\rho_{\mathrm{s}} h_{\mathrm{s}} v_{y}\right)=\phi_{\mathrm{m}}-\phi_{\mathrm{s}} \\
& \frac{\partial}{\partial t}\left(\rho_{\mathrm{s}} h_{\mathrm{s}} v_{x}\right)+\frac{\partial}{\partial x}\left(\rho_{\mathrm{s}} h_{\mathrm{s}} v_{x}^{2}\right)+\frac{\partial}{\partial y}\left(\rho_{\mathrm{s}} h_{\mathrm{s}} v_{x} v_{y}\right)=\left(\rho_{\mathrm{s}}-\rho_{\mathrm{a}}\right) g h_{\mathrm{s}} \sin \beta_{x} \\
& -\frac{1}{2} \frac{\partial}{\partial x}\left(\left(\rho_{\mathrm{s}}-\rho_{\mathrm{a}}\right) g h_{\mathrm{s}}^{2} \cos \beta_{x}\right)+\mathbf{R}_{x}+\phi_{\mathrm{m}} u_{x}-\phi_{\mathrm{s}} v_{x} \\
& \frac{\partial}{\partial t}\left(\rho_{\mathrm{s}} h_{\mathrm{s}} v_{y}\right)+\frac{\partial}{\partial x}\left(\rho_{\mathrm{s}} h_{\mathrm{s}} v_{x} v_{y}\right)+\underbrace{\frac{\partial}{\partial y}}_{\partial y}\left(\rho_{\mathrm{s}} h_{\mathrm{s}} v_{y}^{2}\right)=\underbrace{\left(\rho_{\mathrm{s}}-\rho_{\mathrm{a}}\right) g h_{\mathrm{s}} \sin \beta_{y}}_{(1)} \\
& -\frac{1}{2} \frac{\partial}{\partial y}\left(\left(\rho_{\mathrm{s}}-\rho_{\mathrm{a}}\right) g h_{\mathrm{s}}^{2} \cos \beta_{y}\right)+\underbrace{\mathbf{R}_{y}}_{(3)}+\underbrace{\phi_{\mathrm{m}} u_{y}}_{(4)}-\underbrace{\phi_{\mathrm{s}} v_{y}}_{(5)}
\end{aligned}
$$

Eq. 5 and 6 describe the volume and mass balances (per square meter) for a current whose density varies and whose thickness is not affected by particle settling [Doyle et al., 2010]. Equations 7 and 8 are the momentum balances. The right-hand terms of Eq. 7 and 8 mean (1) that the surge can move on a slope due to its weight because it is denser than the atmosphere. It can also move by spreading (2), even on a horizontal surface. The third term (3) includes the stresses that resist to the displacement and the last terms (4) and (5) take into account the momentum gain and lost by exchanges with the concentrated part. Note that no overpressure is taken into account and that blast effects cannot be simulated.

Here, $h_{\mathrm{s}}$ is the thickness of the dilute current, $\mathbf{v}=\left(v_{x}, v_{y}\right)$ its velocity and, $\beta_{x}$ and $\beta_{y}$ the slope of the surface formed by the ground plus the concentrated flow in the $x$ and $y$ directions. The density of the surge varies and can be close to the density of the atmosphere, $\rho_{\mathrm{a}}$, which cannot be neglected (Eq. 7-8). The density of the mixture of gas and particles that moves from the concentrated flow to the dilute current is termed $\rho_{\mathrm{m}}$ (see section 2.3). As for the concentrated 
flow, the two terms at the right-hand side of each equation take into account the mass exchange, here between the dilute current and, the concentrated flow or deposit (see section 2.4). The surge is considered to exhibit turbulent drag stress [e.g. Bonnecaze et al., 1993; Bonnecaze and Lister, 1999; Hogg and Pritchard, 2004; Doyle et al. 2008], R, expressed by:

$$
\mathbf{R}=-a_{2} \rho_{s}\|\mathbf{v}\| \mathbf{v}
$$

where $a_{2}$ is a drag coefficient that relates the velocity of the flow to the drag stress exerted by the turbulence. The set of equations (5) to (8) is valid only where the density of the ash-cloud is higher than the density of the atmosphere, with the ash-cloud behaving as a density current (i.e. an ash-cloud surge).

Air entrainment can have a strong influence on the surge emplacement [Bursik and Woods, 2000; Andrews, 2014]: atmospheric gases are ingested by the flow, become heated and thus decrease the surge density. Air ingestion will increase the flow thickness, simultaneously decreasing the flow density [e.g. Hallworth et al., 1996]. Thus, the term $\rho_{\mathrm{s}} h_{\mathrm{s}}$ that rules the dynamics of the flow (Eq. 6-8) will not drastically change and, while the density of the surge is significantly higher than the density of the atmosphere, entrainment influences the flow thickness but probably only has a secondary effect on the emplacement (see section 3.7). Air entrainment is not taken into account in the model as in the approach of Doyle et al. [2008; 2010]. This assumption affects the model accuracy for very dilute surges and at the edges of dense surges where air ingestion can decrease the surge density down to the atmosphere density, causing the ash-cloud to become buoyant. 


\subsection{Mass and momentum exchanges: from the concentrated to the dilute current}

During the emplacement of the concentrated flow, particles at its surface can be put into suspension to form a mixture of gas and particles that supplies the ash-cloud, changing its thickness and its density (Fig. 1). A number of processes have been proposed for particle transfer from the concentrated flow to the dilute current: (1) turbulence [Denlinger, 1987] (2) elutriation [Fisher, 1979; Wilson, 1980]; (3) decompression of pressurized volcanic gases [Woods et al., 2002]; (4) entrainment by heated atmospheric gases [Mc Taggart, 1960; Sparks, 1976; Wilson and Walker, 1982]; (5) particle collisions [Spark et al., 1978; Fujii and Nakada, 1999]. The gas of the mixture can originate either from the concentrated flow or from entrainment and heating of the atmosphere. The density of the mixture, which takes these phenomena implicitly into account, is termed $\rho_{\mathrm{m}}$ and the mass flux (per $\mathrm{m}^{2}$ of the surface and per s) of gas and particles forming this mixture and supplying the dilute current is termed $\phi_{\mathrm{m}}$. It is impossible to carry out direct measurements of particle exchanges (mass flux rate, the grain size distribution, etc.) between the concentrated and the dilute parts of natural pyroclastic currents. Wind tunnel experiments, in which an air flux is imposed above a granular layer, are useful to understand, at least partially, the mechanisms involved in particle entrainment into a saltation layer. The experiments show that the air flux interacts with the roughness caused by the grains of the granular layer surface and becomes turbulent [Denlinger, 1989]. This turbulence plays an important role in particle mobilization by wind [e.g. Bagnold, 1941]. While various laws can be found in the literature, the mass flux of particles, per square meter, is often considered to be a function of the wind velocity cubed, with no flux below a minimal velocity value [Bagnold, 1941; Pye and Tsoar,1990; Tegen and Fung, 1995; Tegen and Miller, 1997; Uno et al., 2001; Xuan, 2004]. This threshold is generally low (some tens of cm / s) compared to concentrated pyroclastic flow velocities $(>20 \mathrm{~m} / \mathrm{s})$ and here it is assumed to be zero for a sake of simplification. 
The mass flux of the gas and particle mixture, $\phi_{\mathrm{m}}\left(\right.$ in $\left.\mathrm{kg} / \mathrm{m}^{2} / \mathrm{s}\right)$, which leaves each square meter of the surface of the concentrated part to supply the dilute part, is thus modelled by:

$$
\phi_{\mathrm{m}}=a_{3} \mathbf{u}^{3}
$$

where $a_{3}$ is a parameter that relates the mass flux of particles to the concentrated flow velocity (in $\mathrm{kg} \mathrm{s}^{2} \mathrm{~m}^{-5}$ ). Eq. 10 certainly highly simplifies reality, the natural mass flux being potentially complicated by particle collisions, grinding, shocks and hydraulic jumps related to the concentrated flow displacement, by the high temperature and the gas content of the concentrated flow and its degasing, and by the density and velocity of the overlying surge [Wilson and Walker, 1982]. Since we do not know the influence of these parameters, we use the simplest equation form deduced from available experiments, while recognizing that more researches are needed to better defined the physical processes involved.

The mixture of particles and gases (atmospheric and lost from the concentrated flow) change both the surge density and its thickness (Fig. 1). The thickness of the surge varies locally with time:

$$
\frac{d h_{s}}{d t}=\frac{\phi_{m}}{\rho_{m}}
$$

The product of the surge density multiplied by its thickness, $\rho_{s} h_{s}$, i.e. the mass of the surge per surface unit, also varies according to $\phi_{m}$ :

$$
\frac{d\left(\rho_{s} h_{s}\right)}{d t}=\phi_{m}
$$

The new surge density is deduced from equations (11) and (12). In the model, the surge velocity is constant perpendicular to the ground and our depth-averaged approach implicitly assumes that vertical mixing is locally instantaneous across the dilute current thickness. 
Simultaneously, considering that the mass of the entrained atmosphere is small compared to the mass of gas and particles lost from the concentrated flow, the flow thickness decreases according to $\phi_{\mathrm{m}}$ and to its density, $\rho_{\mathrm{d}}$ :

$$
\frac{d h_{d}}{d t}=-\frac{\phi_{m}}{\rho_{d}}
$$

The flux of momentum is calculated from the mass flux $\phi_{m}$ and the velocity of the concentrated part $\|\mathbf{u}\|$. The concentrated flow will lose in momentum $\phi_{m}\|\mathbf{u}\|$ by per square meter and per second, and the dilute current will gain the same momentum. The velocity of the concentrated flow is not affected by the particle flux because mass and momentum decrease together. However, this mass transfer can modify the surge velocity.

\subsection{Mass and momentum exchanges: from the dilute to the concentrated flow}

The settling velocity, $w_{\text {sed, }}$ of particles in a surge depend on their density, shape and size, and is often given by:

$$
w_{\text {sed }}=\sqrt{\frac{4\left(\rho_{p}-\rho_{s}\right) g d_{p}}{3 C_{d} \rho_{s}}}
$$

[Le Roux, 1992; Sparks et al., 1997; Dellino et al., 2005, and references therein]. where $\rho_{\mathrm{p}}$ is the density of particles, $d_{\mathrm{p}}$ their diameter and $C_{\mathrm{d}}$ a drag coefficient. The mass of particles lost by sedimentation (per square meter) depends on this settling velocity $W_{\text {sed, }}$ the volumetric fraction of particles $C_{\mathrm{v}}$ and the density of the particles $\rho_{\mathrm{p}}$ :

$$
\phi_{\mathrm{s}}=c_{v} \rho_{p} w_{\mathrm{sed}}
$$


The surge density is given by $\rho_{\mathrm{s}}=c_{v} \rho_{p}+\left(1-c_{v}\right) \rho_{g}$, where $\rho_{\mathrm{g}}$ is the density of the hot gas (from volcanic and/or atmospheric origin) of the surge. Note that $\rho_{\mathrm{s}}$ decreases progressively to $\rho_{\mathrm{g}}$ as the surge loses particles by sedimentation. Because the volumetric fraction of particles is given by:

$$
c_{v}=\left(\rho_{\mathrm{s}}-\rho_{g}\right) /\left(\rho_{p}-\rho_{g}\right) \approx\left(\rho_{\mathrm{s}}-\rho_{g}\right) / \rho_{p}
$$

Eq. 15 becomes:

$$
\phi_{\mathrm{s}}=\left(\rho_{\mathrm{s}}-\rho_{g}\right) w_{\mathrm{sed}}
$$

The local variation of the mass of the surge per square meter, $\rho_{\mathrm{s}} h_{\mathrm{s}}$, through time due to sedimentation is then given by:

$$
\frac{d\left(\rho_{s} h_{s}\right)}{d t}=-\phi_{s}=-\left(\rho_{s}-\rho_{g}\right) w_{\text {sed }}
$$

To solve equation 18, we follow the assumption of Doyle et al. [2010] (their equations 2a-2c) which considers that the sedimentation does not affect the surge thickness but only its density. Where the density of the surge becomes lighter than the atmosphere, the ash-cloud should lift off. The model then considers that the particles of the ash-cloud leave the system at the point where lift-off should occur and the surge thickness is locally set to zero.

The mass lost by the surge can form a deposit, be added to the existing concentrated flow or form surge-derived concentrated flows [Calder et al., 1999; Druitt et al., 2002]. This depends on the thickness of mass deposited, the topographic slope and the rheological parameters chosen for the concentrated part.

The mass of particles lost by the surge equals the mass gained by the concentrated part (concentrated flow or deposit) and is given by:

$$
\frac{d\left(\rho_{d} h_{d}\right)}{d t}=-\frac{d\left(\rho_{s} h_{s}\right)}{d t}=\phi_{s}=\left(\rho_{s}-\rho_{g}\right) w_{\mathrm{sed}}
$$


Because the density of the concentrated part is considered to be constant, equation 12 can be simplified to:

$$
\frac{d h_{d}}{d t}=\frac{\left(\rho_{s}-\rho_{g}\right)}{\rho_{d}} w_{\mathrm{sed}}
$$

\subsection{Numerical resolution of the equations}

The system of equations is solved using the VolcFlow code [Kelfoun and Druitt, 2005; Kelfoun et al., 2009], which was developed for the simulation of depth-averaged flows on DEMs. The code has been highly modified to take into account two fluids simultaneously (the concentrated and the dilute currents), the laws simulating the mass and momentum exchanges (Eq. 10-20), and the density variations of the surge (Eq. 6-8).

\section{Results}

The parameters of the following simulations are listed in Tab. 1. If not specified, the parameters used are realistic values either obtained by field measurements or estimated by reproducing natural events in the companion paper [Kelfoun et al., submitted].

\subsection{Characteristics and evolution of the dilute current}

In the model, the surge characteristics depend on the mass, momentum and density of the mixture formed by the concentrated flow, and on the particles lost by sedimentation. The following section illustrates how equations 10 and 17 affect the characteristics of the dilute part. For this first example, no lateral displacement is taken into account: the mass of the dilute part 
comes from the underlying concentrated part and subsequently settles on it. Nevertheless, to be consistent with the other sections, the term surge is used to refer to the dilute part.

Figure 2 a shows the influence of the surge density and of the flow velocity on the mass balance that controls the surge evolution. The bold curve shows the equilibrium between the mass lost by sedimentation and the mass gained from the concentrated flow. To the right of the bold curve, values are positive and indicate that the mass elutriated from the concentrated flow is higher than the mass lost by sedimentation so that the surge mass increases. To the left, the mass balance is negative: the mass flux from the concentrated flow is insufficient to compensate the mass flux lost by sedimentation and either the concentrated flow cannot form a surge or an existing surge loses mass until it disappears. The density of the surge has two antagonistic effects on the sedimentation: first, it reduces the settling velocity of a given particle (Eq. 14). However, because a higher density also means a larger concentration of particles, more particles settle out, thus increasing the mass lost (Eq. 17). Fig 2a shows that the second effect dominates and that a higher surge concentration increases the mass lost. This is true up to a concentration of about $1000 \mathrm{~kg} / \mathrm{m}^{3}$, which is much higher than the density of a surge. However, except for low density surges $\left(<5 \mathrm{~kg} / \mathrm{m}^{3}\right)$, the density has a relatively small influence compared to the velocity of the concentrated flow. The bold curve shows that, with the parameters chosen (Tab. 1), a velocity of the pyroclastic flow of about $15-25 \mathrm{~m} / \mathrm{s}$ is needed to generate and maintain a surge.

Figure $2 \mathrm{~b}$ shows the same mass transfer rates according to the velocity of the concentrated flow and to different particle sizes. Negative values mean that the surge loses mass and tends to disappear. The null flux, where the mass lost equals the mass gained, is represented in bold for a surge density of $10 \mathrm{~kg} / \mathrm{m}^{3}$. Two other null-flux curves for a surge density of $1.1 \mathrm{~kg} / \mathrm{m}^{3}$ and 2 $\mathrm{kg} / \mathrm{m}^{3}$ are represented by the dashed and the dotted lines, respectively. Fig. $2 \mathrm{~b}$ also demonstrates the existence of a threshold in surge formation at around 15-25 m/s. Below this velocity, the 
mass flux from the concentrated flow is very low and is always lower than the mass lost, even for very fine particles.

Note that another condition for surge generation is that the particles can be held in suspension and can be mixed homogeneously through the whole surge thickness. It is commonly assumed that a particle can be held in suspension if its Rouse number $P_{n}=\frac{w_{\text {sed }} k}{V_{*}}$ is lower than 2.5, with $V^{*}$ the shear velocity (in the order of magnitude of the surge velocity $\|\mathbf{v}\|$ ) and $k$ the Von Karman constant, equal to 0.4 [Valentine, 1987; Dellino et al, 2008]. The capacity for homogeneous mixing can be estimated using the Stokes number, which is a ratio of the characteristic response times for particles to the fluid turbulence [e.g. Elghobashi, 1994; Sijercic et al, 2007]. The Stokes number is defined by $S t k=\frac{t_{0} v_{0}}{\ell_{0}}$, where $v_{0}$ is the characteristic velocity of the vortices, $\ell_{0}$ their characteristic length and $t_{0}$ is the relaxation time of the particle defined by $t_{0}=\frac{\rho_{p} d_{p}^{2}}{18 \mu_{s}}$ with $\mu_{\mathrm{s}}$ the surge viscosity. For $S t k<<1$, particles closely follow fluid streamlines and can be mixed homogeneously. Particles smaller than $0.1 \mathrm{~mm}$ in diameter, as often found in surge deposits, are easy to be put into suspension $\left(P_{\mathrm{n}}<2.5\right)$ and mixed homogeneously $(S t k<<1)$, while particles larger than $1 \mathrm{~cm}$ can only be mixed under more exceptional conditions (large eddies, high surge viscosity, low particle density). This should be kept in mind so as not to over interpret the upper part of Fig. 2 b.

\subsection{Surge genesis from a concentrated flow}

Equations of mass fluxes are now coupled with Eqs. 1-3 and 5-8 to be studied dynamically. In the first simulation, in 1D (Fig. 3a-b), a mass representing a concentrated flow is released in one go onto a slope in order to approximate a dome collapse. For visibility, a high value of $T_{0}$ 
has been chosen so as to create a thick flow. The flow rheology contains a plastic term (Eq. 4), meaning that there is a relation between its thickness and its ability to flow. Where the flow is thick, the driving stresses (related to the slope and the thickness) are higher than the retarding stress (which is constant) and the flow accelerates (Eq. 2). The high flow velocity induces a flux of particles (Eq. 10) that forms a surge when it becomes greater than the mass flux lost by sedimentation (Eq. 17). The mass of the surge increases and the surge acquires its own dynamics (Eq. 7-8). The concentrated flow thins until the driving stress becomes lower than the resisting stress and the velocity decreases until the flow stops. Fewer particles are emitted from the flow and the density of the dilute current decreases rapidly through sedimentation. However, its density can be high enough to enable the dilute current to surpass the front of the concentrated flow (Fig. 3b). The dilute part stops when its density equals the density of the atmosphere and the mass lifts off. Thus, depending on the topography and on the characteristics of the concentrated and the dilute parts (rheological parameters, mass rate, volume, etc.), the dilute current can be slower (Fig. 3a) or faster (Fig. 3b) than the concentrated flow and can stop before or after the runout reached by the concentrated flow.

\subsection{Concentrated flow genesis from a surge}

In the simulation shown in Fig. 3c-d a surge is continuously created from the border of the calculation domain to mimic, for example, a column collapse. The surge moves downstream and progressively loses mass by sedimentation, resulting in a decrease in density. The runout of the surge is determined by the point at which the density of the surge equals the density of the atmosphere (Fig. 3d). Initially, this mass lost by sedimentation of the surge forms a deposit (i.e. a static concentrated part). But, because the thickness of the concentrated part increases with time, the driving stress of the weight increases until the concentrated part begins to flow (Fig. 3d). Concentrated flow genesis occurs in pulses: the mass lost by the surge accumulates 
on the ground until it is able to flow, then builds up again to the point at which it flows again. The concentrated part is able to exceed the surge runout (Fig. 3d).

\subsection{Influence of the slope on surge genesis}

The influence of the slope on the surge generated by the concentrated flow in the model can first be analyzed in stationary conditions with a purely plastic rheology. The influence of the turbulent stress (Eq. 4) is generally of secondary importance and is set here to zero.

A concentrated flow reaches a constant velocity when the driving force equals the resisting force. For a purely plastic rheology, and a flow whose thickness does not vary spatially, a stationary state (no variation of $h$ over time) is reached when the driving force equals the plastic basal stress:

$$
\rho g h \sin \alpha=\tau_{0}
$$

This gives the thickness needed by the flow to reach a constant velocity:

$$
h=\frac{\tau_{0}}{\rho g \sin \alpha}
$$

A thicker flow will accelerate to thin and thus reach the equilibrium thickness. Conversely, a thinner flow will decelerate to thicken.

In this simple analysis the valley is considered to be horizontal perpendicular to the valley axis with vertical walls. For a volumetric rate $Q$ of pyroclastic flow, the stationary velocity is given by:

$$
u=\frac{Q}{h w}=\frac{Q \rho g \sin \alpha}{\tau_{0} w}
$$

where $w$ is the valley width. Using Eq. 10, the mass flux from the concentrated flow to the dilute current is then: 


$$
\phi_{\mathrm{m}}=a_{3} \mathbf{u}^{3}=a_{3}\left(\frac{Q \rho g \sin \alpha}{\tau_{0} w}\right)^{3} \quad \quad\left(\text { per } \mathrm{m}^{2} \text { and per } \mathrm{s}\right)
$$

The mass flux that forms the surge is very sensitive to the concentrated flow velocity and, consequently, to all the parameters that control this velocity, one of which is the slope. For example, increasing the slope from $10^{\circ}$ to $30^{\circ}$ increases the mass flux by about 25 . Decreasing the slope from $10^{\circ}$ to $5^{\circ}$ decreases the mass flux by about 8 .

Another illustration of this slope effect is given by a dynamic analysis of the model (full set of equations). A first simulation is done on a constant slope of $5^{\circ}$. The valley is linear downslope and is defined by a sinusoidal cross section ( $\lambda=50 \mathrm{~m}, \delta=20 \mathrm{~m}$, Fig. $4 \mathrm{a})$. The concentrated flow is generated at the left side of the domain $(x=0)$. It accelerates to reach $\sim 12 \mathrm{~m} / \mathrm{s}$ and generates a dilute current that overflows the valley. With the parameters chosen (Tab. 1), the surge reaches a maximal density of $\sim 9 \mathrm{~kg} / \mathrm{m}^{3}$ above the flow, and because its density decreases rapidly it moves laterally by about $70 \mathrm{~m}$ from the concentrated part (Fig. $4 \mathrm{~b}$ ). Streamlines show that the surge that covers a given area is generated in the proximal area covered by the flow (downstream displacement of less than $100 \mathrm{~m}$ ).

The simulation in Fig. 4c is done with the same slope and the same valley shape but a steeper slope of $30^{\circ}$ is added at a distance of $200 \mathrm{~m}$. The effect of the steeper slope is to accelerate the flow and this occurs even before the break in slope: because the mass on the steeper slope accelerates, the thickness gradient changes. This adds an additional driving stress to the concentrated flow (Eq. 2-3) and the mass accelerates, propagating the thickness change and the acceleration upstream of the break in slope. On the steeper slope the mass accelerates from 12 $\mathrm{m} / \mathrm{s}$ to about $22 \mathrm{~m} / \mathrm{s}$ and forms a thick, concentrated surge that spreads out in the downstream area and is able to flow faster than the concentrated flow. The surge formed on the steep slope is able to progress more than $500 \mathrm{~m}$ downstream. 
The surge deposits are $12 \%$ of the initial flow volume for the $5^{\circ}$ slope and $30 \%$ for the steeper slope. This mass is removed from the flow and, because the flow stop is related to its thickness, a smaller volume means a shorter runout of the flow (not visible for the domain size of Fig. 4).

\subsection{Influence of river constriction on surge genesis}

If a river narrows in a steady state configuration, the volumetric rates of pyroclastic flow are equal before and after the constriction:

$$
Q=u_{w} h_{w} w=u_{W} h_{w} W
$$

where $w$ and $W$ are the valley widths and $u_{\mathrm{w}}, h_{\mathrm{w}}, u \mathrm{w}$ and $h \mathrm{w}$ are the flow velocity and thickness before and after the constriction, respectively. The thickness and/or the velocity need then to increase to compensate for the reduction in width. With a purely plastic rheology, we have seen that a flow tends to a given thickness for which the driving stress equals the retarding stress and the velocity reaches a steady state. Immediately after the constriction, the flow tends to accelerate to reach the same thickness as before the constriction and $h_{w}=h_{W}$. The velocity after the constriction is then related to the velocity before the constriction by:

$$
u_{w}=\frac{u_{W} W}{w}
$$

The mass flux from the flow to the surge depends on the velocity to the power of three. Then,

after the constriction, the mass flux will increase by a factor $\left(\frac{W}{w}\right)^{3}$. For example, a reduction of the drainage width by 2 will change the mass flux by 8 . Conversely, widening of a valley will decrease the surge genesis.

The effect of a drainage constriction on surge production is simulated by the model in Fig. 5ab. Downstream of the constriction, the valley is sinusoidal (Fig. 4a). Upstream, the central line of the drainage has been enlarged by a 100-m wide incline. 
Before the constriction, the velocity calculated by the model with the parameters chosen is about $8 \mathrm{~m} / \mathrm{s}$, whereas afterwards it is about $30 \mathrm{~m} / \mathrm{s}$. With the parameters chosen (Tab. 1) the mass flux $\phi_{m}$ changes from 5 to $270 \mathrm{~kg} / \mathrm{m}^{2} / \mathrm{s}$. The mass flux of $5 \mathrm{~kg} / \mathrm{m}^{2} / \mathrm{s}$ is not high enough to compensate the mass lost by particle settling and a very thin surge is created. However, after the constriction, the mass flux of $270 \mathrm{~kg} / \mathrm{m}^{2} / \mathrm{s}$ is larger than the mass lost by particle settling and a surge can form. The surge leaves the drainage to flow over several tens of meters on the interfluves. Thus, the model shows that variations in valley width can have a strong influence of the surge genesis and dynamics.

\subsection{Decoupling between the currents}

Concentrated flows are more sensitive to meter-scale topography than thick, dilute currents. Thus decoupling between the two flows often occurs at river bends. The following topography was used to check if the model could reproduce this decoupling: a sinusoidal valley cross section, with the first part of the valley linear and parallel to the slope (Fig. 5c), after which the valley curves by $45^{\circ}$ before returning to the downslope orientation. The curve follows a circle with a radius of $100 \mathrm{~m}$. Using the chosen parameters (Tab. 1), the concentrated flow formed is about $2.5 \mathrm{~m}$ thick with a velocity of $\sim 15 \mathrm{~m} / \mathrm{s}$. The mass and volume of the surge increase progressively (max. thickness $\sim 25 \mathrm{~m}$ ). When the current reaches the bend, the surge continues straight forward onto the interfluves, apart from a small part which follows the drainage (Fig. 5d). The concentrated part follows the drainage because its thickness and velocity at the bend, with the parameters chosen, are too low to flow onto the interfluves. It is thus decoupled from the main surge. After the bend, the flow still generates the surge but, due to the lower flow velocity related to its thinning, the new surge formed is thinner and only overflows the 
interfluves immediately adjacent to the main drainage (Fig. 5e). As shown in figure 5e the thickest surge deposits are found downstream and along the projection of the upstream valley.

\subsection{Influence of the density of the surge $\left(\rho_{s}\right)$ and of the mixing $\left(\rho_{\mathrm{m}}\right)$}

Simulation were carried out using the same parameters as for Fig $5 \mathrm{c}-\mathrm{e}$, the only difference being the value of $\rho_{\mathrm{m}}$, the density of the gas-particle mixture that leaves the concentrated flow to form the surge. The value of $\rho_{\mathrm{m}}$ controls the value of the surge density $\rho_{\mathrm{s}}$. However, it does not affect the mass flux which remains constant. A low value of $\rho_{\mathrm{m}}$ thus forms a thick, dilute surge while a high value forms a thin, dense surge. Comparing the two results (see supplementary material) shows that the densities of the surge and of the mixture play a secondary role in the dynamics of the surge: the shape of the deposit is similar for a surge density of about $10 \mathrm{~kg} / \mathrm{m}^{3}$ and 20 $\mathrm{kg} / \mathrm{m}^{3}$. This can be explained by Eqs. $7-8$ which show that the main parameter that governs the surge dynamics is the local mass $\left(\rho_{\mathrm{s}} h_{\mathrm{s}}\right)$. A thick, light surge has the same mass as a thin, concentrated surge. This conclusion is not valid if surge thickness is close to the depth of the valley: surge can be strongly influenced by the valley shape and can be confined above the concentrated flow. The conclusions are not valid either for very light surges, which rapidly reach the density of the atmosphere. The results justify a posteriori that air entrainment can be considered of second importance as long as the surge density is significantly higher than the atmosphere density.

\subsection{Influence of the mass rate}

Since surge genesis is related, in the model, to the velocity of the concentrated flow, any parameter that causes an increase in the flow velocity also increases the surge production. As 
explained in the previous sections, a thick flow moves faster than a thin flow. For a given volume of flow, a short duration of formation, and consequently a high volumetric rate, forms thicker flows than low volumetric rates. Thus high volumetric rates are related to faster flows and to more powerful surges.

Simulations carried out with various volumes and volumetric rates show that, close to the source, the principal influence is the mass rate, which controls the velocity of the flow. The areas affected by the surges are similar whatever the volumetric rate and are poorly dependent on the volume. Downstream, however, the velocity reaches an equilibrium. It is no longer influenced by the initial velocity and thus by the mass rate. Here, the velocity and the runout are mainly controlled by the volume of the flow, with a larger volume allowing the concentrated part to flow and to create a surge far from the source.

\subsection{Change of surge extension with valley infill}

Field observation indicate that the valley infill, which decreases the valley's depth, seems to play a role in the destruction of the surrounding interfluves by ash-cloud surges [Komorowski et al., 2013; Ogburn et al., 2014]. To evaluate the effect of the valley depth on the surge emplacement, simulations were done with the same geometry as for the simulation in Fig. $4 \mathrm{~b}$ (a 20-m-deep valley, slope $5^{\circ}$ ) but with the addition of a 50 -m high plateau bounding the drainage on half of the calculation domain (closer to the source, Fig. 5f). Remind that such a topography creates high curvatures that lower the model accuracy. This is, however, interesting to explore the model behavior. In the valley surrounded by the plateau, the surge formed with a mixing density $\rho_{\mathrm{m}}$ of $10 \mathrm{~kg} / \mathrm{m}^{3}$ is too thin to flow out of the 50 -m-deep valley. The surge remains essentially channeled above the flow and particles settle onto it. With more width between the plateau edges and the drainage, the particles can form a thick deposit at the sides 
of the flow and the model shows that the presence of a surrounding topography favours particle accumulation and, consequently, the formation of surge-derived concentrated flows.

At the downstream end of the deep part, the surge is able to spread out onto the interfluves (Fig. 5f). However, because the surge has settled progressively, the surge thickness and density are not very different to what they would have been without the plateau. With a density $\rho_{\mathrm{m}}$ of 2 $\mathrm{kg} / \mathrm{m}^{3}$, the same mass flux forms a thicker surge that can overflow the $50-\mathrm{m}$ walls of the drainage. However, the edges that bound the flow still play a major role in the surge emplacement, and the distance reached by the surge is strongly reduced $(150 \mathrm{~m}$ from the valley on the plateau, and $300 \mathrm{~m}$ from the valley elsewhere).

\section{Discussion}

\subsection{Compatibility of the model with field observations}

Our understanding of the coupling between concentrated and dilute currents as well as the physics of these currents remains very incomplete, as pointed out by Ogburn et al. [2014]. A way to improve our understanding of the physics is to make models, and try to reproduce field observations as closely as possible by changing the model parameters, and then by interpreting the values and the laws obtained.

Ash-cloud surges are known to be more powerful and to overrun the concentrated flow after traversing a break in slope. For example, this has been described at Santiguito, Guatemala [Rose et al., 1977], at Ngauruhoe [Nairn and Self, 1978] and at Merapi, Indonesia [Kelfoun et al., 2000; Lube et al., 2011; Jenkins et al., 2013]. The tree directions measured following the 1994 eruption of Merapi [Kelfoun et al., 2000] are entirely compatible with the results of Fig. 4. Surges are also known to detach from the concentrated flow at valley bends [Yamamoto et al., 1993; Fujii and Nakada, 1999; Kelfoun et al., 2000; Charbonnier and Gertisser, 2008; Lube et 
al., 2011; Komorowski et al., 2013]. Loughlin et al. [2002] described the formation of surges after valley constrictions. A strong negative correlation between the valley cross-sectional area and the area covered by detached surges has been demonstrated by Ogburn et al. [2014]. Our model reproduces this effect (Fig. 5b). Their observation that a critical cross-section exists in reality is compatible with the critical velocity needed by the model to form a surge $(\sim 20 \mathrm{~m} / \mathrm{s})$. The critical section of Ogburn et al. [2014] might then be explained by the velocity needed to allow a given volumetric rate to flow across a given valley width. Cole et al. [2002] studied the pyroclastic flows of Montserrat and concluded that there is no direct relationship between the volume of pyroclastic flows and the area covered by surges. This is consistent with the results of the model that the volumetric rate plays a more crucial role in the surge genesis than the volume itself.

\subsection{Influence of the parameters on surge dynamics}

The model has been developed to be as simple as possible. Nevertheless, because it aims to capture the first order behavior of a natural complex phenomenon, about 20 parameters need to be defined. Some of them are known, or can be calculated or estimated in the field (e.g. volume of the flow, gravity, concentrated flow density, topography). But five parameters cannot be directly estimated: the rheological parameters of the concentrated flow ( $T_{0}$ and $a_{1}$, Eq. 4$)$, the turbulent coefficient of the surge ( $a_{2}$, Eq. 9 ), the parameter $a_{3}$ (Eq. 10) that governs the exchange between the concentrated flow and the surge, and the density of the mixture that supplies the surge ( $\rho_{\mathrm{m}}$, Eq. 11). This section explains how they can be estimated from field observations.

$T_{0}$ and $a_{1}$ control the flow emplacement and can be estimated relatively easily. $T_{0}$ controls the thickness of the concentrated deposit. A high value forms thick, short deposits, a low value forms thin, long deposits. The parameter $a_{1}$ influences the concentrated flow velocity, and an 
increase in this value slows down the simulated flows. On a complex topography, the velocity and thus the value of $a_{1}$ can be estimated depending on whether the flow can cross a given morphology. The results are strongly influenced by the choice of the plastic rheology as a proxy for the complex rheology of pyroclastic flows. The advantage of the plastic rheology compared to the Coulomb law is that is reproduces the correlation between the flow thickness and it flow capacity. This is probably why it successfully reproduces the emplacement of natural pyroclastic flows [Kelfoun et al., 2009; Charbonnier et al., 2013] as well as debris avalanches [Kelfoun and Druitt, 2005; Kelfoun, 2011]. Other rheological laws that would reproduce this correlation would lead to similar results.

The variable $a_{2}$ controls the surge velocity. It can be estimated using direct observations of the velocity or from the destruction, related to this velocity and to the surge density. The ratio of the length of the surge to its width can be also used to define $a_{2}$. A low value of $a_{2}$ tends to increase the length of the surge downstream.

Variable $a_{3}$ determines the mass flux from the concentrated flow and is estimated from the mass of surge deposits. With a high value of $a_{3}$, a large mass of particles from the concentrated flow is passed to the surge, and voluminous surge deposits are formed. This parameter implicitly takes into account phenomena that act on the surge genesis (temperature, pore pressure, etc.). Future work must define this dependence more quantitatively, must better explain the mechanism responsible of the particle exchanges, which is certainly more complex than saltation, and must confirm or improve Eq. 10.

Mixture density $\rho_{\mathrm{m}}$ determines the thickness of the surge and, consequently, its density. It can be estimated by the elevation reached by the surge along the hills, by the capacity of the surge to flow over the topography or from the estimation of the surge density (using the dynamic pressure for example, Jenkins et al. 2013). 


\section{Conclusion}

A new model has been developed to simulate concentrated pyroclastic flows, pyroclastic surges and their interactions, using two coupled depth-averaged approaches. The analysis of the model behavior shows that the approach and the equations used make it possible to reproduce the behavior of the natural current, at least qualitatively. The model mimics the genesis of surges from concentrated flows and the formation of deposits, and of surge-derived concentrated flows through sedimentation of the surge. It shows that a velocity of about $25 \mathrm{~m} / \mathrm{s}$ is needed for a concentrated flow to form a surge. All the parameters that increase the concentrated flow velocity can thus be lead to surge formation. This explains the strong influence of the topography on the surge genesis: a break in slope or a river constriction can dramatically influence the surge genesis by accelerating the velocity of the concentrated flow. The model also shows that the volume rate can be more important for the surge genesis than the volume itself. The strong correlation between the volumetric rate and surge genesis can be particularly problematic for hazard assessment. In the case of dome collapse, for example, knowing the dome volume would not be enough in itself to estimate the areas covered by resultant surges. The volumetric rate is a critical parameter and depends on the way the dome collapses, which is difficult to predict, and could explain the sudden genesis of powerful surges, the difficulty of predicting their subsequent damage, and the potential danger for the population. The model must now be tested against real field cases in order to check its ability to quantitatively reproduce natural phenomenon. In a companion paper [Kelfoun et al., submitted], we show that the model is able to reproduce the extension, the thickness and the emplacement of the 2010 PDCs of Merapi volcano. 


\section{Notation}

$\begin{array}{ll}a_{1} & \mathrm{u}^{2} \text {-stress coefficient for the flow, Eq. } 4 \\ a_{2} & \text { turbulent stress coefficient for the surge, Eq. } 9 \\ a_{3} & \text { mass flux coefficient to the surge, Eq. } 10 \\ C_{\mathrm{d}} & \text { drag coefficient of surge particles } \\ c_{\mathrm{V}} & \text { volumetric fraction of particles } \\ g & \text { gravity } \\ h_{\mathrm{d}} & \text { flow thickness } \\ h_{\mathrm{s}} & \text { surge thickness } \\ t & \text { time } \\ \mathbf{T}=\left[T_{x}, T_{y}\right] & \text { total resisting stress for the flow } \\ \mathbf{R}=\left[R_{x}, R_{y}\right] & \text { total resisting stress for the surge } \\ \mathbf{u}=\left[u_{x}, u_{y}\right] & \text { flow velocity } \\ \mathbf{v}=\left[v_{x}, v_{y}\right] & \text { surge velocity } \\ w_{\mathrm{sed}} & \text { settling velocity of surge particles } \\ x & x \text {-direction along the slope } \\ y & y \text {-direction along the slope } \\ \alpha_{x}, \alpha_{y} & \text { topographic slope in } x \text { and } y \\ \beta_{x}, \beta_{y} & \text { slope of the flow surface in } x \text { and } y \\ \phi_{\mathrm{m}} & \text { mass flux from the flow to the surge } \\ \phi_{\mathrm{s}} & \text { mass flux lost by settling from the surge } \\ \rho_{\mathrm{a}} & \text { atmosphere density } \\ \rho_{\mathrm{d}} & \text { flow density } \\ \rho_{\mathrm{g}} & \text { gas density in the surge } \\ \rho_{\mathrm{m}} & \text { mixture density from the flow to the surge } \\ \rho_{\mathrm{p}} & \text { particles density } \\ \rho_{\mathrm{s}} & \text { surge density }\end{array}$

\section{Acknowledgement}

This work has be founded by the Domerapi - ANR (French Agence Nationale de la Recherche) Project (ANR-12-BS06-0012). The is the LabEx ClerVolc contribution $n^{\circ} 249$. The data for this paper are available by contacting the corresponding author at k.kelfoun@opgc.fr. I am very grateful to both Dr. Tomaso Esposti Ongaro and an anonymous reviewer for their constructive remarks. 


\section{References}

Andrews, B., J. (2014), Dispersal and air entrainment in unconfined dilute pyroclastic density currents, Bulletin of Volcanology 76 (9), 1-14.

Bagnold, R., A. (1941). The Physics of Blown Sand and Desert Dunes. Methuen, London.

Beget, J., E. and A. J. Limke (1988), Two-dimensional kinematic and rheological modeling of the 1912 pyroclastic flow, Katmai, Alaska. Bulletin of Volcanology 56, 148-160.

Bernard, J., K. Kelfoun, J. L. Le Pennec, S. Vallejo Vargas (2014), Pyroclastic flow erosion and bulking processes: comparing field-based vs. modeling results at Tungurahua volcano, Ecuador. Bulletin of Volcanology vol.76, p.858, doi:10.1007/s00445-014-0858-y.

Breard, E., C., P., G. Lube, J. R. Jones, J. Dufek, S. J. Cronin, G. A. Valentine, and A. Moebis (2016), Coupling of turbulent and non-turbulent flow regimes within pyroclastic density currents, Nat. Geosc., 9, 767-771, doi: 10.1038/NGEO2794.

Bursik, M., I. and A.W. Woods (1996), The dynamics and thermodynamics of large ash flows. Bull. Volcanol. 58, 175-193.

Bursik, M., I., A. W. Woods (2000), The effects of topography on sedimentation from particleladen turbulent density currents, J. Sedimentary Res., 70 (1).

Bonnecaze, R., H. Huppert, and J. Lister (1993), Particle-driven gravity currents, J. Fluid Mech., 250, 339-369.

Bonnecaze, R., and J. Lister (1999), Particle-driven gravity currents down planar slopes, J. Fluid Mech. (1999), vol. 390, pp. 75-91.

Bourdier, J.-L., and E. K. Abdurachman (2001), Decoupling of small volume pyroclastic flows and related hazards at Merapi volcano, Indonesia. Bulletin of Volcanology, 63, 309-325, http://dx.doi.org/10.1007/s004450100133.

Branney, M., J. and P. Kokelaar (2002), Pyroclastic Density Currents and the Sedimentation of Ignimbrites, Vol. 27 of Memoirs. Geological Society, London, UK.

Calder, E., S., P. D. Cole, W. B. Dade, T. H. Druitt and R. Hoblitt (1999), Mobility of pyroclastic flows and surges at the Soufrie're Hills Volcano, Montserrat. Geophysical Research Letters, 26, 537-540, http://dx.doi.org/10.1029/1999GL900051.

Castro-Orgaz, O., K. Hutter, J. V. Giraldez, and W. H. Hager (2015), Nonhydrostatic granular flow over 3-D terrain: New Boussinesq-type gravity waves?, J. Geophys. Res.: Earth. Surf., 101, 1, 1-28, doi: 10.1002/2014JF003279.

Charbonnier, S., J., and R. Gertisser (2008), Field observations and surface characteristics of pristine block-and-ash flow deposits from the 2006 eruption of Merapi Volcano, Java, Indonesia. Journal of Volcanology and Geothermal Research, 177, 971-982, http://dx.doi. org/10.1016/j.volgeores.2008.07.008. 
Charbonnier, S., J., and R. Gertisser (2012), Evaluation of geophysical mass flow models using the 2006 block-and-ash flows of Merapi Volcano, Java, Indonesia: towards a shortterm hazard assessment tool, J. Volcanol. Geotherm. Res., 231-232, 87-108.

Charbonnier, S., J., A. M. Germa, C. B. Connor, R. Gertisser, K. Preece, J.-C. Komorowski, F. Lavigne, T. H. Dixon, and L. J. Connor (2013), Evaluation of the impact of the 2010 pyroclastic density currents at Merapi volcano from high-resolution satellite imagery, field investigations and numerical simulations, J. Volcanol. Geotherm. Res., 261, 295-315.

Cole, P., D., E. S. Calder, et al. (2002), Deposits from dome-collapse and fountain-collapse pyroclastic flows at Soufrière Hills Volcano, Montserrat. In: Druitt, T. H. \& Kokelaar, B. P. (eds) The Eruption of Soufrière Hills Volcano, Montserrat, from 1995 to 1999. Geological Society, London, Memoirs, 21, 231-262, http://dx.doi.org/ 10.1144/GSL.MEM.2002.021.01.11.

Córdoba, G., E. B. Pitman, and M. F. Sheridan (2015), TITAN2F: a pseudo-3-D model of 2phase debris flows, Nat. Hazards Earth Syst. Sci. Discuss., 3, 3789-3822, doi:10.5194/nhessd3-3789-2015.

Dartevelle, S., W. I. Rose, J. Stix, K. Kelfoun, and J. W. Vallance (2004), Numerical modeling of geophysical granular flows: 2. Computer simulations of plinian clouds and pyroclastic flows and surges, Geochemistry Geophysics Geosystems 5, Q08004, doi:10.1029/2003GC000637.

Dellino, P., D. Mele, R. Bonasia, G. Braia, L. La Volpe, and R. Sulpizio (2005), The analysis of the influence of pumice shape on its terminal velocity, Geophys. Res. Lett., 32, L21306, doi:10.1029/2005GL023954.

Dellino, P., D. Mele, R. Sulpizio, L. La Volpe, and G. Braia (2008), A method for the calculation of the impact parameters of dilute pyroclastic density currents based on deposit particle characteristics, J. Geophys. Res., 113, B07206, doi:10.1029/2007JB005365.

Denlinger, R., P. (1987), A model for generation of ash clouds by pyroclastic flows, with application to the 1980 eruptions at Mount St. Helens, Washington. Journal of Geophysical Research, 92, 284-298, http://dx.doi.org/10.1029/JB092iB10p10284.

Doyle, E., E., A. J. Hogg, H. M. Mader, and R. S. J. Sparks (2008), Modeling concentrated pyroclastic basal flows from collapsing columns. Geophysical Research Letters, 35, 1-5, http://dx.doi.org/10.1029/2007GL032585.

Doyle, E., E., A. J. Hogg, H. M. Mader, R. S. J. Sparks (2010), A two-layer model for the evolution and propagation of concentrated and dilute regions of pyroclastic currents, $\mathrm{J}$. Volcanol. and Geotherm. Res., 190 (2010) 365-378.

Druitt, T., H. (1998), Pyroclastic density currents. In: Gilbert, J., Sparks, R. (Eds.), The Physics of Explosive Volcanic Eruptions. : Geological Society, London, Special Publications, 145. Geological Society, London, pp. 145-182.

Druitt, T., H., E. S. Calder, P. D. Cole, R. P. Hoblitt, S. C. Loughlin, G. E. Norton, L. J. Ritchie, R. S. J. Sparks and B. Voight (2002), Small-volume, highly mobile pyroclastic flows formed by rapid sedimentation from pyroclastic surges at Soufrière Hills Volcano, Montserrat: an 
important volcanic hazard. In: Druitt, T.H., Kokelaar, B.P. (Eds.), The Eruption of Soufriere Hills Volcano, Montserrat, from 1995 to 1999, 21. Geol. Soc. Mem. Geol. Soc. of London, London, pp. 263-279.

Druitt, T., H. and R. S. J. Sparks (1982), A proximal ignimbrite breccia facies on Santorini, Greece. J. Volcanol. Geotherm. Res. 13, 147-171.

Elghobashi, S. (1994), On Predicting Particle-Laden Turbulent Flows, Applied Scientific Research 52: 309-329, 1994. 309.

Esposti Ongaro, T., A. Neri, G. Menconi, M. de'Michieli Vitturi, P. Marianelli, C. Cavazzoni, G. Erbacci, P.J. Baxter (2008), Transient 3D numerical simulations of column collapse and pyroclastic density current scenarios at Vesuvius, Journal of Volcanology and Geothermal Research, 178, 3, 378-396.

Esposti Ongaro, T., A. B. Clarke, B. Voight, A. Neri, and C. Widiwijayanti (2012), Multiphase flow dynamics of pyroclastic density currents during the May 18, 1980 lateral blast of Mount St. Helens. Journal of Geophysical Research 117: doi: 10.1029/2011JB009081. issn: 01480227.

Fisher, R., V. (1979), Models for pyroclastic surges and pyroclastic flows. J. Volcanol. Geotherm. Res. 6, 305-318.

Fisher, R., V. (1995), Decoupling of pyroclastic currents: hazards assessments. Journal of Volcanology and Geothermal Research, 66, 257-263, http://dx.doi.org/10.1016/03770273(94)00075-R.

Fujii, T., and S. Nakada (1999), The 15 September 1991 pyroclastic flows at Unzen Volcano (Japan): a flow model for associated ash-cloud surges. Journal of Volcanology and Geothermal Research, 89, 159-172, http://dx.doi.org/10.1016/S0377-0273(98)00130-9.

Gray, J., M., N., T., Y.-C. Tai, and S. Noelle (2003), Shock waves, dead zones and particle-free regions in rapid granular free-surface flows, J. Fluid Mech., 91, 161- 181.

Gueugneau, V., K. Kelfoun, O. Roche, and L. Chupin (2017), Effects of pore pressure in pyroclastic flows: Numerical simulation and experimental validation, Geophys. Res. Lett., 44, doi:10.1002/2017GL072591.

Hallworth, M., A., H. E. Huppert, J. C. Phillips, and R. S. J. Sparks (1996), Entrainment into two-dimensional and axisymetric gravity currents, J. Fluid Mech., 308, $289-311$.

Heinrich, P., G. Boudon, J. C. Komorowski, R. S. J. Sparks, R. Herd, and B. Voight (2001), Numerical simulation of the December 1997 debris avalanche in Montserrat, Lesser Antilles, Geophys. Res. Lett., 28, 2529-2532.

Hogg, A., J., and D. Pritchard (2004), The effects of hydraulic resistance on dam-break and other shallow inertial flows, J. Fluid Mech., 501, 179-212.

Hutter, K., Y. Wang, and S. P. Pudasaini (2005), The Savage-Hutter avalanche model: how far can it be pushed? Philos. Trans. A Math Phys. Eng. Sci., 363, 1832, 1507-28. 
Itoh, H., J. Takahama, M. Takahashi, and K Miyamoto (2000), Hazard estimation of the possible pyroclastic flow disasters using numerical simulation related to the 1994 activity at Merapi Volcano, J. Volcanol. Geotherm. Res., 100, 1, 503-516, doi:10.1016/S03770273(00)00153-0.

Iverson, R., M., and R. P. Denlinger (2001), Flow of variably fluidized granular masses across three-dimensional terrain: 1. Coulomb mixture theory, J. Geophys. Res., 106, 537-552, doi:10.1029/2000JB900329.

Jenkins, S., J.-C. Komorowski, P. Baxter, R. Spence, A. Picquout, F. Lavigne, and Surono (2013). The Merapi 2010 eruption: An interdisciplinary impact assessment methodology for studying pyroclastic density current dynamics, J. Volcanol. Geotherm. Res., 261 (1), 316-329.

Kelfoun K. (2011), Suitability of simple rheological laws for the numerical simulation of concentrated pyroclastic flows and long-runout volcanic avalanches: Journal of Geophysical Research, Solid Earth, v. 116, p. b08209. doi:10.1029/ 2010JB007622.

Kelfoun, K., and T. H. Druitt (2005), Numerical modeling of the emplacement of Socompa rock avalanche, Chile, J. Geophys. Res., 110, B12202, doi:10.1029/2005JB003758.

Kelfoun, K., V. Gueugneau, J.-C. Komorowski, N. Aisyah and N. Cholik (submitted), Simulation of block-and-ash flows and ash-cloud surges of the 2010 eruption of Merapi volcano with a two-fluid layer model, submitted to J. Geophys. Res.

Kelfoun, K., F. Legros, and A. Gourgaud (2000), A statistical study of trees damaged by the 22 November 1994 eruption of Merapi volcano (Java, Indonesia): relationships between ash-cloud surges and block-and-ash flows, J. Volcanol. Geotherm. Res., 100 (1-4), 379-393.

Kelfoun, K., P. Samaniego, P. Palacios, and D. Barba (2009), Is frictional behaviour suitable for pyroclastic flow simulation: Comparison with a well constrained eruption at Tungurahua volcano (Ecuador), Bull. Volcanol., 71, 1057-1075, doi:10.1007/s00445-009-0286-6.

Komorowski, J.-C., S. Jenkins, P. J. Baxter, A. Picquout, F. Lavigne, S. Charbonnier, R. Gertisser, K. Preece, N. Cholik., A. Budi-Santoso, and Surono (2013), Paroxysmal dome explosion during the Merapi 2010 eruption: Processes and facies relationships of associated high-energy pyroclastic density currents, J. Volcanol. Geotherm. Res., 261 (1), 260-294 Special Issue: Merapi eruption.

Lacroix, A. (1904), La Montagne Pelée et ses eruptions. Masson et Cie, Paris, in French.

Le Roux, J., P., 1992, Settling velocity of spheres : a new appaoch. Sediment. Geol. 81, 11-16.

Lube, G., S. J. Cronin, J.-C. Thouret, and Surono (2011), Kinematic characteristics of pyroclastic density currents at Merapi and controls on their avulsion from natural and engineered channels. Geological Society of America Bulletin, 123, 1127-1140, http://dx.doi.org/10.1130/B30244.1. 
Luca, I., K. Hutter, C. Y. Kuo, and Y. C. Tai (2009), Two-layer models for shallow avalanche flows over arbitrary variable topography, Int. J. Adv. Eng. Sc. and Appl. Math., 1, 2, 99-121, doi: 10.1007/s12572-010-0006-7.

Luca, I., Y. C. Tai, and C. Y. Kuo, (2016), Shallow Geophysical Mass Flows down Arbitrary Topography, 282 pp, Springer International Publishing, doi: 10.1007/978-3-319-02627-5.

Lucas, A., and A. Mangeney (2007), Mobility and topographic effects for large Valles Marineris landslides on Mars, Geophys. Res. Lett., 34, L10201.

Loughlin, S., C., P. J. Baxter, W. P. Aspinall, B. Darroux, C. L. Harford, and A. D. Miller (2002), Eyewitness accounts of the 25 June 1997 pyroclastic flows and surges at Soufrie're Hills Volcano, Montserrat, and implications for disaster mitigation. In: Druitt, T. H. \& Kokelaar, B. P. (eds) The Eruption of Soufrière Hills Volcano, Montserrat, from 1995 to 1999. Geological Society, London, Memoirs, 21, 211-231, http://dx.doi.org/10.1144/GSL. MEM.2002.021.01.10.

McEwen, A., S. and M.C. Malin (1989), Dynamics of Mount St. Helens' 1980 pyroclastic flows, rockslide-avalanche, lahars, and blast. Journal of Volcanology and Geothermal Research 37, 205-231.

McTaggart, K., C. (1960), The mobility of nuées ardentes. American Journal of Science, 258, 369-382, http://dx.doi.org/10.2475/ajs.258.5.369.

Nairn, I., A., and S. Self (1978), Explosive eruptions and pyroclastic avalanches from Ngauruhoe in February 1975. Journal of Volcanology and Geothermal Research, 3, 39-60.

Nakada, S., T. Fujii (1993), Preliminary report on the activity at Unzen Volcano (Japan), November 1990-November 1991: dacite lava domes and pyroclastic flows. J. Volcanol. Geotherm. Res. 54, 319-333.

Neri, A., and G. Macedonio (1996), Numerical simulation of collapsing volcanic columns with particles of two sizes, Journal of Geophysical Research 101, 8153-8174.

Neri, A., T. Esposti Ongaro, G. Macedonio, and D. Gidaspow (2003), Multiparticle simulation of collapsing volcanic columns and pyroclastic flows. Journal of Geophysical Research 108, 2202, doi:10.1029/2001JB000508.

Ogburn, S., E., E. S. Calder, P. D. Cole, and A. J. Stinton (2014), The effect of topography on ash-cloud surge generation and propagation, Geological Society, London, Memoirs, 39, 179194, doi: 10.1144/M39.10.

Patra, A., K., et al. (2005), Parallel adaptive numerical simulation of dry avalanches over natural terrain, J. Volcanol. Geotherm. Res., 139, 1-21, doi:10.1016/j.jvolgeores.2004.06.014.

Pitman, B., C. C. Nichita, A. Patra, A. Bauer, M. Sheridan, and M. Bursik (2003), Computing granular avalanches and landslides, Physics of Fluids, 15, 12, 3638-3648, DOI: $10.1063 / 1.1614253$. 
Pouliquen, O., and Y. Forterre (2002), Friction law for concentrated granular flows: Application to the motion of a mass down a rough inclined plane, J. Fluid Mech., 453, 133-151.

Pye, K., and H. Tsoar (1990), Aeolian sand and sand dune, Unwin Hyman Limited, London, $396 \mathrm{pp}$.

Rose, W., I. Jr., N. K. Grant, G. A. Hahn, I. M. Lange, J. L. Powel, J. Easter and J. M. DeGraff (1977), The evolution of Santa Maria Volcano, Guatemala. Journal of Geology, 85, 63-87.

Rossano, S., G. Mastrolorenzo, and G. De Natale (2004), Numerical simulation of pyroclastic density currents on Campi Flegrei topography: a tool for statistical hazard estimation. J. Volcanol. Geotherm. Res. 132, 1-14.

Saucedo, R., J. L. Macias, M. F. Sheridan, M. I. Bursik, and J. C. Komorowski (2005), Modeling of pyroclastic flows of Colima Volcano, Mexico: implications for hazard assessment. J. Volcanol. Geotherm. Res. 139, 103-115.

Savage, S. B., and K. Hutter (1989), The motion of a finite mass of granular material down a rough incline, J. Fluid Mech., 199, 177-215.

Sijercic, M., B. Srdjan, and S. Zarko (2007), Simulation of free turbulent particle-laden jet using Reynolds-stress gas turbulence model, App. Math. Model., doi:10.1016/j.apm.2006.03.019.

Sheridan, M. F. and M. C. Malin (1983), Application of computer-assisted mapping to volcanic hazard evaluation of surge eruption: Vulcano, Lipari, and Vesuvius. J. Volcanol. Geotherm. Res. 17, 187-202.

Sheridan, M. F., A. J. Stinton, A. Patra, E. B. Pitman, A. Bauer, and C. C. Nichita (2005), Evaluating Titan 2D mass flow model using the 1963 Little Tahoma Peak avalanches, Mount Rainier, Washington, J. Volcanol. Geotherm. Res., 139, 89-102, doi:10.1016/j.jvolgeores.2004.06.011.

Sparks, R. S. J., S. Self and G.P.L. Walker (1973), Products of ignimbrite eruptions, Geology $1(3), 115-118$.

Sparks, R., M. Bursik, S. Carey, J. Gilbert, L. Glaze, H. Sigurdsson, A. Woods (1997), Volcanic Plumes. Wiley, New Jersey.

Sparks, R., S., J. (1976), Grain size variations in ignimbrites and implications for the transport of pyroclastic flows. Sedimentology 23, 147-188.

Sparks, R., S., J., L. Wilson, and G. Hulme (1978). Theoretical modeling of the generation, movement, and emplacement of pyroclastic density flows by column collapse. Journal of Geophysical Research, 83, 1727-1739, http://dx.doi.org/10.1029/JB083iB04p01727.

Tegen, I., and I. Fung (1995), Contribution to the atmospheric mineral aerosol load from land source modification. Journal of Geophysical Research 100, 18707-18726. 
Tegen, I., and R. Miller (1997), Contribution of different aerosol species to the global aerosol extinction optical thickness; estimates from model results. Journal of Geophysical Research $102,23895-23915$.

Turnbull, B., and P. Bartelt (2003), Mass and Momentum Balance Model of a Mixed Flowing/Powder Snow Avalanche, Surveys in Geophysics 24: 465-477, doi:10.1023/B:GEOP.0000006077.82404.84.

Uno, I., H. Amano, S. Emori, N. Kinoshita, I. Matsu, N. Sugimoto (2001), Trans-Pacific yellow sand transport observed in April 1998: a numerical simulation. Journal of Geophysical Research $106,18331-18344$.

Valentine, G., A., Fisher, R. (1986), Origin of layer 1 deposits in ignimbrites. Geology 14 (2), $146-148$.

Valentine, G., A. (1987), Stratified flow in pyroclastic surges. Bull. Volcanol. 49, 616-630.

Valentine, G. A., and K. H. Wohletz (1989), Numerical models of plinian eruption columns and pyroclastic flows. Journal of Geophysical Research. 94, 1867-1887.

Valentine, G. A., K. H.Wohletz, and, S.W. Kieffer (1992), Effects of topography on facies and compositional zonations in caldera-related ignimbrites. Geological Society of America Bulletin 104, 154-165.

Walker, G., P., L., C.J.N. Wilson (1983), Lateral variations in the Taupo ignimbrite. J. Volcanol. Geotherm. Res. 18, 117-133.

Widiwijayanti, C., B. Voight, D. Hidayat, and S. P. Schilling (2008), Objective rapid delineation of areas at risk from block-and-ash pyroclastic flows and surges, Bull Volcanol, DOI 10.1007/s00445-008-0254-6.

Wilson, C., J., N. (1980), The role of fluidization in the emplacement of pyroclastic flows: an experimental approach. J. Volcanol. Geotherm. Res., 8, 231-249, http://dx.doi.org/10.1016/ 0377-0273(80)90106-7.

Wilson, C., J., N. \& Walker, G. P. L. (1982), Ignimbrite depositional facies: the anatomy of a pyroclastic flow. Journal of the Geological Society, London, 139, 581-592, http://dx.doi.org/10.1144/gsjgs.139.5.0581.

Woods, A., W., R. S. J. Sparks, L. J. Ritchie, J. Batey, C. Gladstone, and M. I. Bursik (2002), The explosive decompression of a pressurized volcanic dome: the 26 December 1997 collapse and explosion of Soufrie re Hills Volcano, Montserrat. In: Druitt, T. H. \& Kokelaar, B. P. (eds) The eruption of Soufrie 're Hills Volcano, Montserrat, from 1995 to 1999. Geological Society, London, Memoirs, 21, 457-465, http://dx.doi.org/10.1144/GSL.MEM.2002.021.01.20.

Xuan, J. (2004), Turbulence factors for threshold velocity and emission rate of atmospheric mineral dust. Atmospheric Environment 38(12): 1777-1783. 
Yamamoto, T., S. Takarada and S. Suto (1993), Pyroclastic flows from the 1991 eruption of Unzen volcano, Japan. Bulletin of Volcanology, 55, 166-175, http://dx.doi.org/10.1007/BF00301514. 


\section{Captions}

Figure 1: Flow diagram of the model. The concentrated flow loses a mass flux $\phi_{s}$ of density $\rho_{\mathrm{m}}$ that forms the dilute current (surge). The dilute current is of variable density and loses a mass flux $\phi_{\mathrm{s}}$ that can form a concentrated flow or a deposit.

Figure 2: (a) Mass fluxes at the interface between the concentrated flow and the surge (in $\mathrm{kg}$ per $\mathrm{m}^{2}$ and per second, values in italic), based on the velocity of the concentrated flow and the surge density. The mass flux to the surge is given by Eq. 10-12 while the mass is lost according to Eq. 14 and 18. The solid curves are drawn for particle diameters of $0.25 \mathrm{~mm}$. The bold curve indicates that the mass gained balances the mass lost (mass balance $=0$ ). Dashed curves correspond to the equilibrium state for particles of $0.1 \mathrm{~mm}$ and $1 \mathrm{~mm}$ in diameter. The dark grey zone corresponds to the area where the dilute mixture is lighter than the atmosphere and lifts off. (b) Mass fluxes between the concentrated flow and the dilute current (in $\mathrm{kg} \mathrm{per} \mathrm{m}^{2}$ and per second) based on the velocity of the concentrated flow and the particle diameter (log scale) for a surge density of $10 \mathrm{~kg} / \mathrm{m}^{3}$. Dashed line: equilibrium state for a density of $2 \mathrm{~kg} / \mathrm{m}^{3}$ and 1.1 $\mathrm{kg} / \mathrm{m}^{3}$.

Figure 3: (a-c) Surge genesis from a concentrated flow. Once generated, the surge has its own dynamics and can overrun the concentrated flow. (a) $t=5 \mathrm{~s}$, (b) $t=15 \mathrm{~s}$. (b-d) Genesis firstly of a concentrated deposit and then of a concentrated flow from the mass lost by the surge. The surge is generated continuously at the left-hand border of the domain with a thickness of $50 \mathrm{~m}$ and a density of $20 \mathrm{~kg} / \mathrm{m}^{3}$. (a) $t=10 \mathrm{~s}$, (b) $t=200 \mathrm{~s}$.

Figure 4: Effect of the topographic slope on the area covered by pyroclastic surges. (a) Cross section of the valley. (b) With a slope of $5^{\circ}$ the surge extends up to $70 \mathrm{~m}$ from the concentrated flow. (c) If a steeper slope is added to the topography, the surge genesis is much stronger. Movie in supplementary material.

Figure 5: (a-b) Downstream of a constriction, the higher velocity of the concentrated flow creates more voluminous surges that can leave the main drainage to overflow the interfluves. (c-e) Decoupling between the concentrated and the dilute current. Images show deposit extent for concentrated and dilute currents at (a) $\mathrm{t}=30 \mathrm{~s}$, (b) $45 \mathrm{~s}$ and (c) at rest (150 s). Movie in 
supplementary material. $\rho_{\text {mix }}=10 \mathrm{~kg} / \mathrm{m}^{3}$. (f) Influence of the valley depth on the surge emplacement. The depth of the valley plays a strong role on the lateral extent of the surge.

Table 1: Parameters used in the simulations. For all the simulations, the value of $\rho_{\mathrm{a}}$ is set at 1 $\mathrm{kg} / \mathrm{m}^{3}$. The values of the particle diameters $d_{\mathrm{p}}$ are given for $C_{d}=1$. For other values of $C_{d}(\mathrm{e} . \mathrm{g}$. Dellino et al. 2008) the particle diameter must be changed to keep the ratio $d_{\mathrm{p}} / C_{\mathrm{d}}$ constant. $g$, gravity; $\rho_{\mathrm{g}}$, density of the gas in the surge; $\rho_{\mathrm{s}}$, surge density; $\rho_{\mathrm{p}}$, particle density; $\rho_{\mathrm{d}}$, concentrated flow density; $\rho_{\mathrm{m}}$, mixing density (section 2.3); $a_{1}$, turbulent/collisional term for the concentrated flow; $a_{2}$, turbulent/collisional term for the surge; $a_{3}$, term for surge genesis; $d_{\mathrm{p}}$, particle diameter; $V$, volume of the concentrated part, $t_{\mathrm{s}}$, duration of current genesis; _c, the value changes and is calculated by the model, ,, parameter not used. All the models described in this article were run in a few minutes on a desktop computer (maximal domain size: $200 \times 500$ meshes, calculation speed: $\approx 1 \mathrm{~s}$ of calculation for $1 \mathrm{~s}$ in reality on a desktop computer, $\approx 15 \mathrm{~min}$ per simulation). 

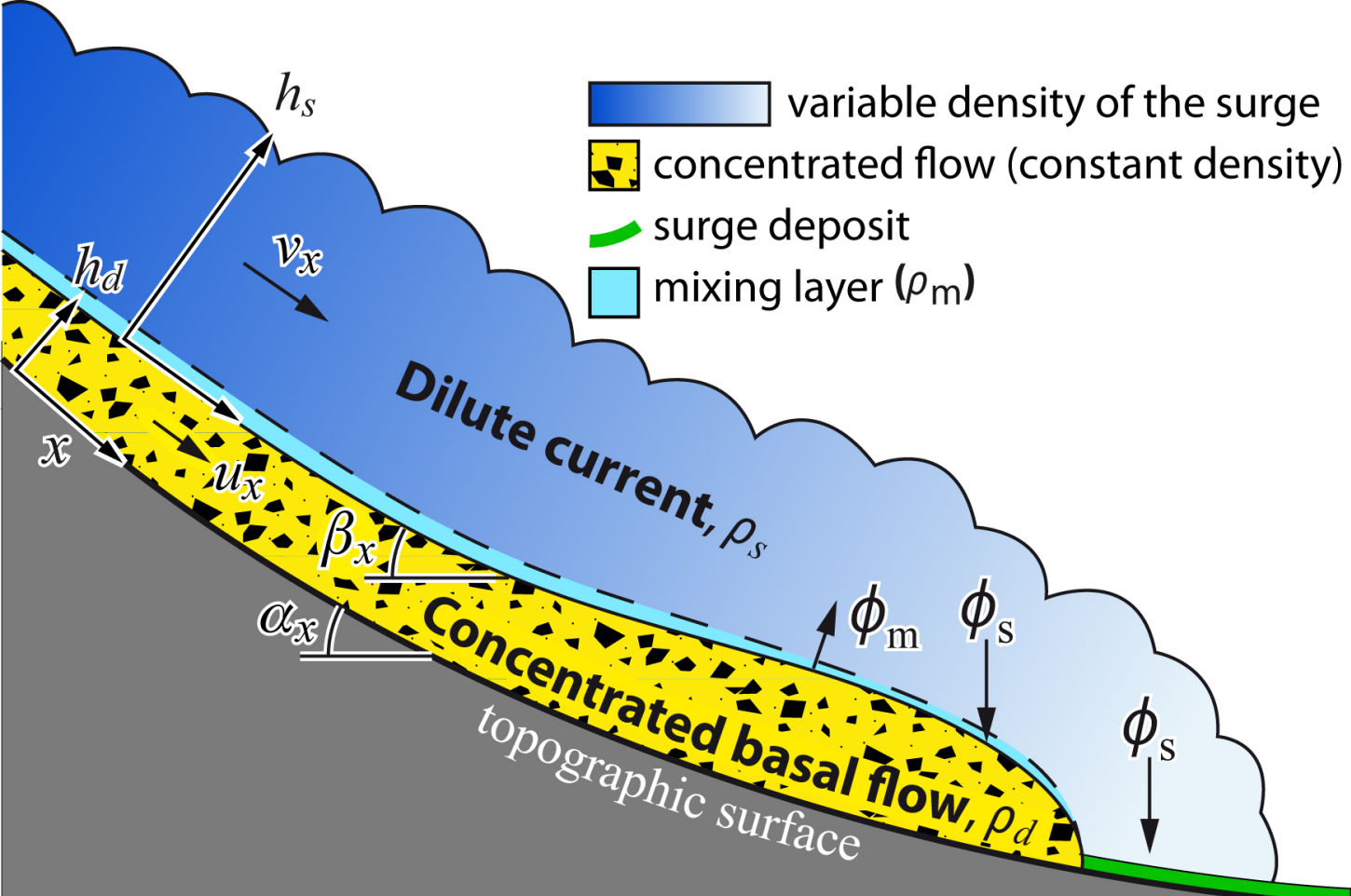


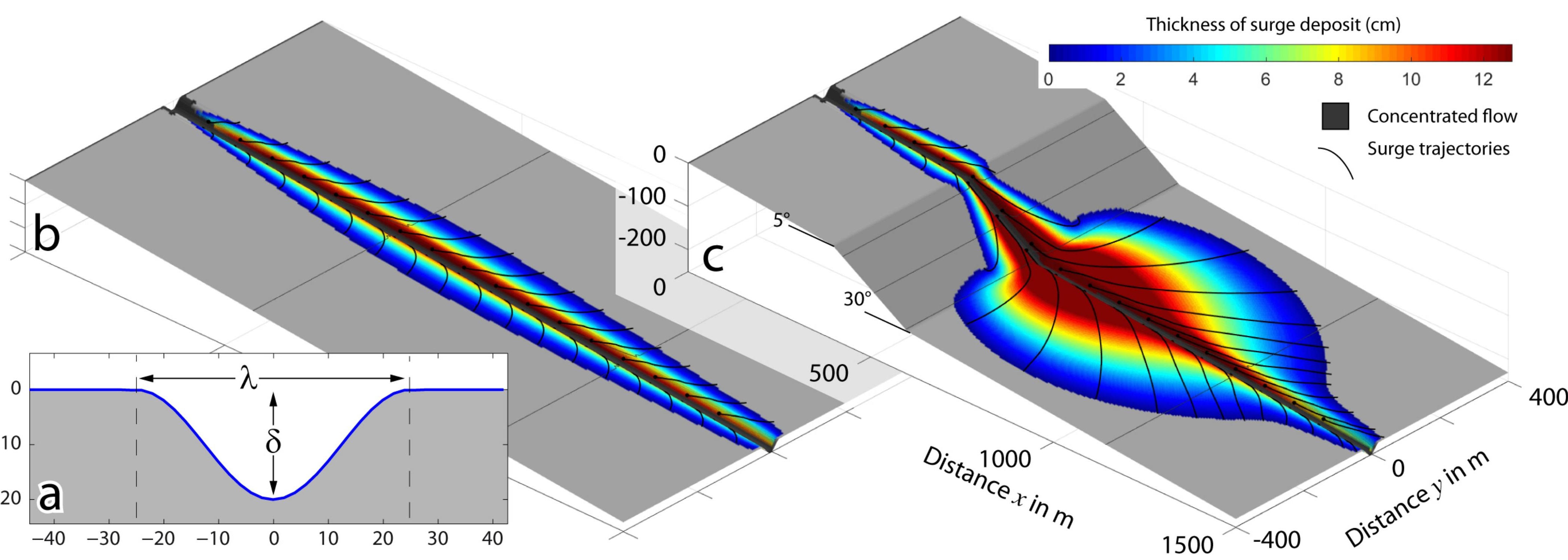




\begin{tabular}{|c|c|c|c|c|c|c|c|c|c|c|c|c|c|c|c|c|}
\hline & $g$ & $\rho_{\mathrm{g}}$ & $\rho_{\mathrm{s}}$ & $\rho_{\mathrm{p}}$ & $\rho_{\mathrm{d}}$ & $\rho_{\mathrm{m}}$ & \multirow{2}{*}{$\frac{T_{0}}{\mathrm{kPa}}$} & \multirow[t]{2}{*}{$a 1$} & \multirow{2}{*}{$\frac{a 2}{-}$} & \multirow{2}{*}{$\frac{a 3}{\mathrm{~kg} \mathrm{~s}^{2} \mathrm{~m}^{-5}}$} & \multirow{2}{*}{$\frac{d_{p}}{m m}$} & $d_{p}$ & v & $t_{\mathrm{s}}$ & $\min (\alpha) \mid$ & $\max (\alpha)$ \\
\hline & $\mathrm{m} / \mathrm{s}^{2}$ & & & $\mathrm{~kg} / \mathrm{m}^{3}$ & & & & & & & & $\phi$ unit & $\mathrm{m}^{3}$ & $\mathrm{~s}$ & - & - \\
\hline Fig. $2 \mathrm{a}-\phi=f\left(\rho_{s}, u\right)$ & 9.81 & 0.5 & $0-20$ & 2000 & - & - & - & - & - & 0.001 & 1 & $\overline{0}$ & - & - & $\overline{0}$ & $\overline{0}$ \\
\hline Fig. $2 b-\phi=f(d, u)$ & 9.81 & 0.5 & 10 & - & - & - & - & - & - & 0.001 & $0.01-100$ & $-6.6-6.6$ & - & - & 0 & 0 \\
\hline Fig. 3ab - Surge from flow & 9.81 & 0.64 & _C & 2400 & 1600 & 10 & 20 & 0.01 & 0.2 & 0.01 & 10 & -3.32 & $1334 \mathrm{~m}^{3} / \mathrm{m}$ & 0 & 0.38 & 45 \\
\hline Fig. 3cd - Flow to surge & 9.81 & 0.64 & _c & 2400 & 1600 & 10 & 10 & 0.01 & 0.2 & 0.01 & 10 & -3.32 & $\sim 2600 \mathrm{~m}^{3} / \mathrm{m}$ & $200 \mathrm{~s}$ & 0.38 & 45 \\
\hline Fig. 4 - break in slope & 9.81 & 0.64 & _c & 2400 & 1600 & 10 & 4 & 0.01 & 0.2 & 0.01 & 0.0625 & 4 & 100000 & 60 & 5 & 30 \\
\hline Fig. 5ab - constriction & 9.81 & 0.64 & _c & 2400 & 1600 & 10 & 4 & 0.01 & 0.2 & 0.01 & 0.0625 & 4 & 100000 & 60 & 10 & 10 \\
\hline Fig. 5c-e - bend, $\rho_{\text {mix }} 10$ & 9.81 & 0.64 & _c & 2400 & 1680 & 10 & 4 & 0.01 & 0.1 & 0.01 & 0.0625 & 4 & 40000 & 60 & 20 & 20 \\
\hline Fig. $5 f$ - in a deep valley & 9.81 & 0.64 & _c & 2400 & 1600 & 10 & 4 & 0.01 & 0.2 & 0.01 & 0.0625 & 4 & 200000 & 30 & 5 & 5 \\
\hline
\end{tabular}


Table 1: List of variables used

\begin{tabular}{llll}
\hline$\alpha_{x}, \alpha_{y}$ & topographic slope in $x$ and $y$ & $a_{3}$ & mass flux coefficient to the surge, Eq. 10 \\
$\beta_{x}, \beta_{y}$ & slope of the flow surface in $x$ and $y$ & $C_{\mathrm{d}}$ & drag coefficient of surge particles \\
$\phi_{\mathrm{m}}$ & mass flux from the flow to the surge & $c_{\mathrm{v}}$ & volumetric concentration of particles \\
$\phi_{\mathrm{s}}$ & mass flux lost by settling from the surge & $g$ & gravity \\
$\rho_{\mathrm{a}}$ & atmosphere density & $h_{\mathrm{d}}$ & flow thickness \\
$\rho_{\mathrm{d}}$ & flow density & $h_{\mathrm{s}}$ & surge thickness \\
$\rho_{\mathrm{g}}$ & gas density in the surge & $t$ & time \\
$\rho_{\mathrm{m}}$ & mixture density from the flow to the surge & $\mathbf{T}=\left[T_{x}, T_{y}\right]$ & total resisting stress for the flow \\
$\rho_{\mathrm{p}}$ & particles density & $\mathbf{R}=\left[R_{x}, R_{y}\right]$ & total resisting stress for the surge \\
$\rho_{\mathrm{s}}$ & surge density & $\mathbf{u}=\left[u_{x}, u_{y}\right]$ & $\begin{array}{l}\text { flow velocity } \\
\end{array}$ \\
$a_{1}$ & turbulent stress coefficient for the flow, Eq. 4 & $\mathbf{v}=\left[v_{x}, v_{y}\right]$ & surge velocity \\
$a_{2}$ & turbulent stress coefficient for the surge, Eq. 9 & $w_{\mathrm{sed}}$ & settling velocity of surge particles \\
& & $y$ & $x$-direction along the slope \\
& & & $y$-direction along the slope
\end{tabular}


Journal of Geophysical Research - Solid Earth

Supporting Information for

A two-layer depth-averaged model for both the dilute and the concentrated parts of pyroclastic currents

Karim Kelfoun

Université Clermont Auvergne, CNRS, IRD, OPGC, Laboratoire Magmas et Volcans, F-63000 Clermont-Ferrand, France.

\section{Contents of this file}

Figures S1

\section{Additional Supporting Information (Files uploaded separately)}

Captions for Movies S2 to S3

\section{Introduction}

The supporting information presents an additional simulation and two movies whose caption are in the manuscript. 


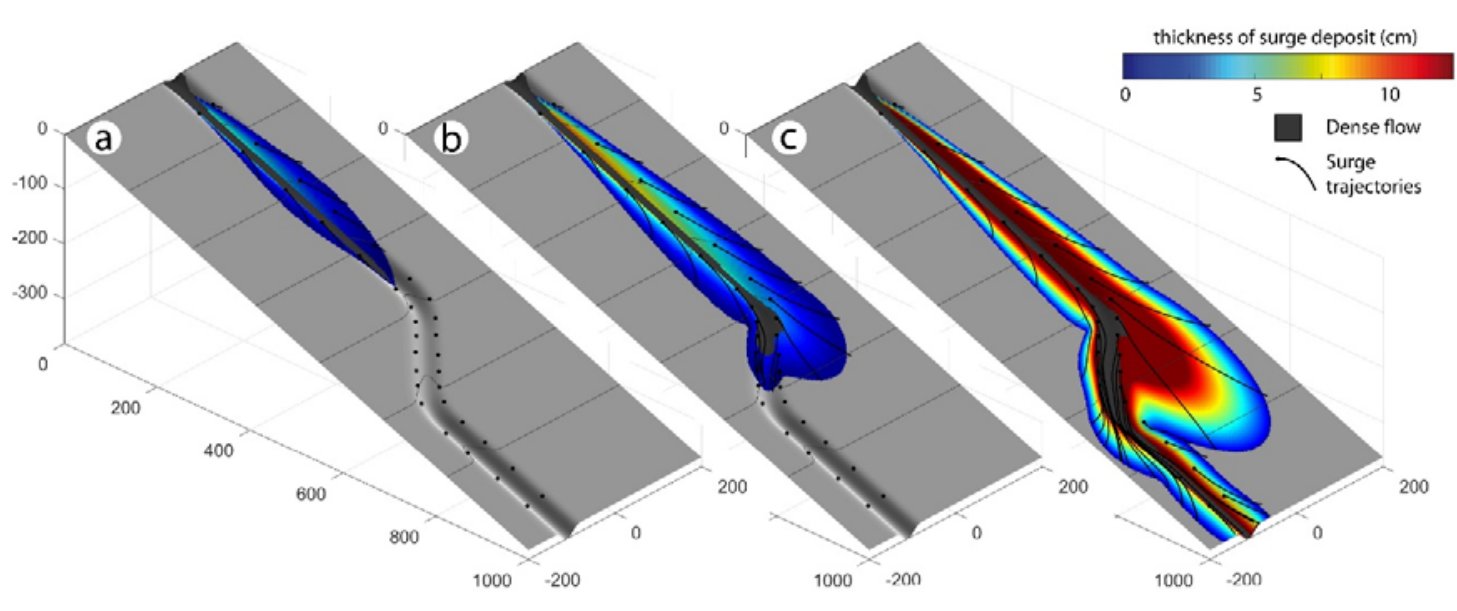

Figure S1. Emplacement of a surge for a surge density twice that of Fig. 5c-e: (a) $t=30 \mathrm{~s}$, (b) $45 \mathrm{~s}$ and (c) at rest (150 s). $\rho_{\text {mix }}=20 \mathrm{~kg} / \mathrm{m}^{3}$.

Movie S2. Movie of the simulation presented in Fig. 4. Effect of the topographic slope on the area covered by pyroclastic surges.

Movie S3. Movie of the simulation presented in Fig. 5c-e. Decoupling between the dense and the dilute flow. 